\title{
Alleviation of Brain Injury-Induced Cerebral Metabolic Depression by Amphetamine: A Cytochrome Oxidase Histochemistry Study
}

\author{
Richard L. Sutton, ${ }^{1 \dagger}$ David A. Hovda ${ }^{2}$, Michael J. Chen ${ }^{3}$, and Dennis M. Feeney ${ }^{4}$ \\ ${ }^{\prime}$ Department of Surgery/Neurosurgery, Hennepin County Medical Center Minneapolis, MN; \\ ${ }^{2}$ Division of Neurosurgery, Departments of Surgery and of Molecular and Medical Pharmacology, \\ UCLA School of Medicine, Los Angeles, CA; ${ }^{3}$ Department of Chemistry and Biochemistry, \\ Utah State University, Logan, UT; ${ }^{4}$ Departments of Psychology and Neurosciences, \\ The University of New Mexico, Albuquerque, NM; USA
}

\begin{abstract}
Measurements of oxidative metabolic capacity following the ablation of rat sensorimotor cortex and the administration of amphetamine were examined to determine their effects on the metabolic dysfunction that follows brain injury. Twenty-four hours after surgery, rats sustaining either sham operations or unilateral cortical ablation were administered a single injection of D-amphetamine $(2 \mathrm{mg} / \mathrm{kg}$; i.p.) or saline and then sacrificed $24 \mathrm{~h}$ later. Brain tissue was processed for cytochrome oxidase histochemistry, and 12 bilateral cerebral areas were measured, using optical density as an index of the relative amounts of the enzyme. Compared with that of the control groups, cytochrome oxidase in the injured animals was significantly reduced throughout the cerebral cortex and in 5 of 11 subcortical structures. This injury-induced depression of oxidative capacity was most pronounced in regions of the hemisphere ipsilateral to the ablation. Animals given D-amphetamine had
\end{abstract}

\footnotetext{
†Corresponding author:

Department of Surgery, D3-860, Hennepin County

Medical Center, 701 Park Avenue,

Minneapolis, MN 55415, USA

tel: +1 (612) 347-8769; fax: +1 (612) 337-7372

e-mail: sutto004@maroon.tc.umn.edu
}

less depression of oxidative capacity, which was most pronounced bilaterally in the cerebral cortex, red nucleus, and superior colliculus; and in the nucleus accumbens, caudateputamen, and globus pallidus ipsilateral to the ablation. The ability of $D$-amphetamine to alleviate depressed cerebral oxidative metabolism following cortical injury may be one mechanism by which drugs increasing noradrenaline release accelerate functional recovery in both animals and humans.

\section{KEYWORDS}

cerebral oxidative metabolism, diaschisis, stroke, remote functional depression; cytochrome oxidase

\section{INTRODUCTION}

Short term treatment(s) with D-amphetamine (AMPH), when administered late after a unilateral sensorimotor cortex ablation, embolic stroke, or traumatic brain injury (TBI) and combined with physical therapy (PT), results in an enduring acceleration of recovery from hemiplegia in rats and cats (Feeney et al., 1982; Hovda \& Feeney, 1984; Sutton et al., 1987; Feeney \& Westerberg, 1990; Sutton \& Feeney, 1992; Feeney 1998a). 
The efficacy of this experimental treatment protocol may require adjustment of the (a) drug dosage, (b) number of treatments, or (c) delay between injury and initiation of therapy, depending on species, injury severity, and type of injury. Significantly, AMPH treatment may be contraindicated after damage to some brain regions producing motor symptoms, such as cerebellar deep nuclei (Boyeson \& Feeney, 1991) or the substantia nigra (Mintz \& Toner, 1989). In rats with unilateral sensorimotor cortex ablation, a single low dose of AMPH combined with PT, given one day after surgery, significantly enhances functional recovery (Feeney et al., 1982; Goldstein, 1988; Sutton \& Feeney, 1992). Rats with embolic or photothrombotic stroke require multiple and/ or higher doses of AMPH, beginning 1 day after infarct, to promote functional recovery from hemiplegia (Salo \& Feeney, 1987; Hurwitz et al., 1991). Cats with unilateral or bilateral frontal lobe ablation require three high doses of AMPH, beginning 10 days after injury, for drug-induced acceleration of beam-walking recovery to occur (Hovda \& Feeney, 1984; Sutton et al., 1989b). In a few clinical trials, this beneficial effect of treatment with AMPH + PT was extended to hemiplegic stroke patients, with preliminary work on aphasic stroke patients (Walker-Batson et al., 1992; 1995; for review, see Goldstein, 1993; Feeney, 1997; 1998a; 1998b). The recovery from hemiplegia of patients receiving short-term treatment with AMPH + PT, begun as long as 1 month after stroke, was significantly enhanced when compared with that of patients given placebo + PT. Significantly, this benficial effect of a 10-week treatment was enduring because it remained significant for months after discontinuing treatment for the 1-year period of study (Walker-Batson et al., 1995). This opportunity to delay treatment for stroke or TBI is very important because it allows the physician time to make a full evaluation and to stabilize the patients before initiating therapy. Significantly, the vast majority of stroke patients do not seek medical attention within the first 3 to 6 hours after an infarct, when alternative treatments for stroke are most effective (Ginsberg \& Pulsinelli, 1994), and thus can suffer significant side effects (Bath, 1995). Clearly, further development and evaluation of potential therapies that can be initiated late after brain injury to promote recovery are needed.

The mechanism(s) by which AMPH promotes functional recovery after cortical injury are not well understood. It has been established that essential components of AMPH therapy include the release of cerebral noradrenaline (NA) and the provision of PT during the period of drug action. Using the rat model of unilateral sensorimotor cortex ablation, several studies have shown that any of the family of drugs increasing the release of central NA can promote functional recovery when combined with PT (Feeney \& Westerberg, 1990; Goldstein \& Davis, 1990; Feeney, 1991; 1998a; Sutton \& Feeney, 1992; Boyeson \& Harmon, 1993; Goldstein, 1993; Boyeson et al., 1994; Feeney et al., 1994). In addition, intraventricular infusion of NA, but neither dopamine (Boyeson \& Feeney, 1990) nor serotonin (Boyeson et al., 1994; Feeney, personal observations), promotes recovery from hemiplegia after cortical injury. The requirement for PT during the period of drug action to optimize functional recovery after AMPH treatment suggests an interaction between two processes during this experimental treatment. As originally proposed (Feeney et al.; 1985; Feeney \& Sutton, 1987) and subsequently expanded (Feeney, 1998a; 1998b), the two processes involve drug release of the neuromodulator NA which, by alleviating hypometabolic regions, "enables" PT to act upon intact but nonfunctional "performance" circuits that are normally involved in the behaviors that are lost after injury. These afferent inputs are thought to be both proprioceptive feedback and corollary discharges from the attempted movement. The mechanisms resulting from these processes are unknown, but several have been hypothesized, including (a) NA-induced unmasking or permitting the use of alternative pathways (Dietrich et al., 1990), 
(b) enhancing attention by increasing the signalto-noise ratio of unit activity evoked during PT (Segal \& Bloom, 1976a, 1976b; Woodard et al., 1979; Robbins et al., 1985), or (c) enhancing longterm potentiation as a model of plasticity (Gold et al., 1984).

Our own research on the mechanisms of AMPH-induced functional recovery has focused on the ability of this treatment to alleviate an injury-induced metabolic depression in morphologically intact brain tissue, remote from the primary injury. The concept of remote functional depression, or diaschisis, following brain injury has a long history, but only recently have techniques been developed for measuring neuronal function. This evolving concept has been reviewed elsewhere (Feeney \& Baron,1986; Feeney, 1991). Studies reporting that injury to the cerebral cortex produces widespread alterations in both glycolytic (Pappius, 1981; Feeney et al., 1985; Hosokawa et al., 1985; Gilman et al., 1987; Sutton et al., 1989a; Yoshino et al., 1991; Hovda et al., 1996; Queen et al., 1997) and oxidative (Feeney et al., 1985; Hovda et al., 1991; Hovda \& Villablanca, 1998) metabolism substantially support the concept of an injury-induced remote functional depression. In a number of studies, functional recovery from injury-induced neurobehavioral deficits has been correlated with an alleviation of depressed cerebral metabolism (Colle et al., 1986; Gilman et al., 1987; Hovda et al., 1987; Hovda \& Villablanca, 1990; Hovda, 1996).

The concept that producing a functional depression and reduction of neuronal excitability contributes to the symptoms of brain injury is supported by the work of Brailowsky et al. (1986). In his work, Dr. Brailowsky reported that the short-lasting hemiplegia induced by the insertion of saline-filled osmotic minipumps into the sensorimotor cortex of rats was potentiated when the minipumps were filled with GABA. In essence, this worsening of hemiplegia by GABA can be viewed as a drug-induced diaschisis or remote functional depression. Others have reported drug-induced remote functional depression (Khan et al., 1997). During a selective anterior temporal lobe (TL) amobarbital test, aimed at inactivation of the mesiobasal TL structures, the authors measured cerebral glucose utilization using $18 \mathrm{~F}$ fluoro-deoxyglucose positron emission tomography (18F-FDG PET) in temporal lobe epilepsy patients. A decreased glucose uptake resulting from amobarbital application was observed, in addition to the intended ipsilateral anterior TL area. All patients showed decreased glucose uptake in contralateral temporolateral regions, and one-half showed "cerebellar diaschisis". This observation indicates that the simple drug inactivation of local regions produces local and remote metabolic deafferentation. Removal of afferent input is sufficient to produce a diaschisis or hypometabolic response. This simple deafferentation must be included with other postinjury events that are hypothesized to produce remote functional depression, such as sublethal excitotoxicity and sensorimotor imbalance, producing a remote functional depression by altering calcium ion homeostasis (Feeney, 1998a). Whereas all these post-injury events may produce diaschisis, none is essential.

Alleviation of remote metabolic depression after brain injury by drugs increasing cerebral NA has been reported in both the rat (Feeney et al., 1985; Feeney \& Sutton, 1987; 1988; Feeney, 1991; 1998b; Hovda, 1996) and the cat (Hovda et al., 1987). In rat studies addressing the metabolic depression that is associated with fluid percussion TBI, Hovda (1996) reported that the degree and extent of injury-induced depression of cerebral glucose metabolism is a predictor of functional performance on both sensorimotor and cognitive tasks. More important, a single administration of AMPH (3 hours after the injury) alleviates this trauma-induced metabolic depression, complimented by an enhancement in the rate of functional recovery. In addition, widespread depression of local cerebral glucose utilization (ICMRglc) in cortical regions following a cortical freezing lesion is prevented by pre-treatment with drugs that either inhibit serotonin synthesis or block 
alpha 1 -NA receptors (Pappius et al., 1988; Pappius, 1991). The widespread depression of lCMRglc after cortical infarct or TBI is reversed or attenuated by post-injury administration of AMPH, and this metabolic depression continues to be alleviated long after the drug is metabolized (Dietrich et al., 1990; Queen et al., 1997).

The ability of drug-induced NA release to alleviate hypometabolism after brain injury may be one underlying mechanism for the hypothesized permissive action of NA. What mechanisms are involved when PT is provided during NA increase to produce the enduring enhancement of recovery are not understood. Eliminating PT during the period of AMPH action blocks any beneficial effect of the drug on recovery, as has been reported in hemiplegic rats and cats (Feeney et al., 1982; Hovda \& Feeney, 1984; Goldstein \& Davis, $1990)$ and for alleviating some visual deficits in cats following bilateral visual cortex ablation (Feeney \& Hovda, 1985). A possibly related drug/ experience interaction has been described in a PET study of $\mathrm{rCBF}$ in normal human beings who were given a low dose of AMPH before performing different tasks (Mattay et al., 1996). The data from their study indicate that AMPH, rather than having a fixed, global effect on rCBF, induces task-specific activation in selective cortical regions that are involved in the performance of behavioral tasks. This AMPH/experience interaction suggests that the brain area activated by NA depends upon what task the animal or patient is doing during the period of drug action.

Previously, we documented that AMPH can induce an alleviation of a remote functional depression of 1CMRglc, measured 48 hours after either unilateral sensorimotor cortex ablation or TBI in the rat (Feeney et al., 1985; Queen et al., 1997). Other authors have reported that shortterm treatment with AMPH produces an enduring recovery of responsiveness to vibrissae stimulation in a rat model of focal infarct to the cortical vibrissae barrel fields (Dietrich et al., 1990). During the period of AMPH action, alternative neuronal circuits show activation during vibrissae stimulation that is absent during stimulation in normal rats or in injured rats given saline. Given that glycolysis acts independently from oxidative metabolism, a more complete understanding of the effect of AMPH on cerebral metabolic processes following brain injury requires that both metabolic pathways be studied. Little is known, however, regarding the effects of brain injury and AMPH treatment on oxidative metabolism. Therefore, the current study expands our investigations of brain injury and AMPH treatment to oxidative metabolism, examined using cytochrome oxidase (C.O.) histochemistry (Wong-Riley, 1979) to assess the effect of AMPH on cerebral oxidative capacity after brain injury. In the C.O. histochemistry technique, increases in staining intensity reflect increased activity in the mitochondrial cytochrome chain, which relates to energy production in the cell (Wong-Riley, 1989). Previously, we used this method to show that the accelerated recovery of tactile placing, produced by AMPH treatment in cats with bilateral visual cortex ablation, was associated with an enduring increase in C.O. activity in the superior colliculus weeks after the injury (Hovda et al., 1987). The effect of AMPH on oxidative capacity after sensorimotor cortex ablation has not yet been studied, however. Alteration of oxidative capacity after cortical trauma was studied using C.O. histochemistry (Weisend et al., 1990; Hovda et al., 1991). Cortical contusion injury results in oxidative hypometabolism near the injured cortex, as well as in hypermetabolism in the entorhinal cortex and the adjacent temporal lobe (Weisend et al., 1990). It is not clear whether these mixed metabolic effects are related to the numerous pathological events after cortical contusion, but not after ablation, including (a) selective neuronal death of CA3 hippocampal pyramidal and hilar neurons (Feeney et al., 1989), (b) multiple recurring seizures within 3 hours after trauma (Krobert et al., 1992; Nilsson et al., 1994), and (c) slow development of a panecrosis after trauma. The current study was conducted (a) to determine the effects of a 
unilateral sensorimotor cortex ablation on C.O. activity 2 days after injury and (b) to determine the effects of a single AMPH treatment, given one day after cortical injury, on this measure of oxidative capacity.

\section{MATERIALS AND METHODS}

\section{Subjects}

Sixteen male albino rats (Harlan, SpragueDawley, 255 to $290 \mathrm{~g}$ ), maintained in standard wire cages on a 12:12 light:dark cycle and with ad libitum access to food and water, were used in the experiments. All procedures were approved by the University of New Mexico Institutional Review Board.

\section{Surgery and group assignments}

Animals were randomly assigned to sham injury $(\mathrm{N}=8)$ or to ablation $(\mathrm{N}=8)$ groups before surgery. After overnight fasting, the animals were anesthetized with ketamine hydrochloride (60 $\mathrm{mg} / \mathrm{kg}$, i.m.) followed by sodium pentobarbital $(21 \mathrm{mg} / \mathrm{kg}$, i.p.) and positioned in a stereotaxic frame. Animals assigned to injury groups had the right sensorimotor cortex ablated, as described previously (Feeney et al., 1982; Sutton \& Feeney, 1992). Twenty-four hours after surgery, one-half of the animals in the sham (S) and injury (I) groups were injected with either $0.9 \%$ saline (SAL) or AMPH ( $2 \mathrm{mg} / \mathrm{kg}$ in saline, i.p.). The groups were thus designated as S-SAL, S-AMPH, I-SAL; and I-AMPH.

\section{Cytochrome oxidase histochemistry}

Twenty-four hours after SAL or AMPH injection, the animals were overdosed with sodium pentobarbital (100 mg/kg, i.p.) and perfused transcardially with room-temperature $0.9 \%$ saline (pH 7.4), followed by cold fixative solution (2.5\% paraformaldehyde, $1.5 \%$ glutaraldehyde,
$4 \%$ sucrose in $0.1 \mathrm{M}$ phosphate buffer [PB], $\mathrm{pH}$ $7.4,4^{\circ} \mathrm{C}$ ). Brains were post-fixed for $1 \mathrm{~h}$ in cold fixative and then cryoprotected by immersion in succeeding concentrations $(10 \%, 20 \%, 30 \%)$ of sucrose/PB solution at $4^{\circ} \mathrm{C}$. Brains were frozen $\left(-22^{\circ} \mathrm{C}\right)$ and then sectioned in the coronal plane (40-um), and every fifth section throughout the brain was mounted onto gelatin-coated slides. After drying at room temperature, tissue sections were processed for C.O. histochemistry, using the procedure of Wong-Riley (1979). Briefly, sections were reacted for 40 min (in the dark) in an incubation medium $\left(25^{\circ} \mathrm{C}\right)$ consisting of $0.6 \%$ diaminobenzadine (Sigma), $0.2 \%$ cytochrome $\mathrm{C}$, Type III (Sigma), and $4.5 \%$ sucrose in $0.1 \mathrm{M}$ PB (pH 7.4). The reaction was stopped using three rinses in PB; the sections were air-dried and then coverslipped using permount. Tissue sections from all groups were simultaneously reacted in each batch of incubation medium to reduce between-group variability.

For quantifying C.O. activity, optical density readings were taken bilaterally from the 12 gray matter structures listed in Table 1, using a manual densitometer (Sargent-Welch Densichron Model PPD, with a $0.20 \mathrm{~mm}$ diameter aperture). The regions chosen for study of C.O. activity included the extrapyramidal structures previously reported to show altered ICMRglc metabolism after low-dose AMPH (Porrino et al., 1984) and/ or regions showing alterations in ICMRglc or C.O. measures of metabolism after cortical injury and AMPH treatment (Feeney et al. 1985; Hovda et al., 1987; Queen et al., 1997). The readings were taken by an investigator, blinded to the drug treatment conditions of the animals, and were corrected for background (namely, glass, permount, and coverslip). For smaller structures (for example, dorsal tegmental and subthalamic nuclei), a minimum of two to five readings across two to three different sections were taken. For larger structures/regions (for example, cerebral cortex [frontal, parietal, occipital], and the dorsal caudate-putamen), as many as 30 to 38 separate readings from 10 to 15 different sections were 


\section{TABLE 1}

Mean $( \pm S D)$ optical density values $(\times 10)$ for cytochrome oxidase activity in brain structures of the left (L) and right (R) hemisphere for rats with sham injury (S) or right sensorimotor cortex ablation (I) ${ }^{1}$

\begin{tabular}{|c|c|c|c|c|}
\hline \multirow[t]{2}{*}{ Structure } & \multicolumn{4}{|c|}{ Experimental Group } \\
\hline & S-SAL & S-AMPH & I-SAL & I-AMPH \\
\hline Cerebral & L: $262.6(17.7)$ & $220.3(5.8)$ & $188.6(14.3)^{* *}$ & $226.6(16.4)$ \\
\hline Cortex & R: $258.5(19.4$ & $237.0(8.6)$ & $181.4(14.9)^{* *}$ & $221.9(18.5)$ \\
\hline Nucleus & L: $246.3(14.6)$ & $241.0(20.6)$ & $196.4(9.7)$ & $239.7(22.1)$ \\
\hline Accumbens & R: 248.5 (10.3) & $242.0(20.1$ & $197.3(9.0)^{*}$ & $241.4(20.0)$ \\
\hline Caudate & L: 230.7 (15.8) & $225.1(14.1)$ & $190.4(9.4)$ & $220.8(15.0)$ \\
\hline Putamen & R: $230.3(11.8)$ & $228.7(13.0)$ & $192.9(6.5)^{*}$ & $220.7(14.9)$ \\
\hline Globus & L: $189.4(15.0)$ & $166.9(21.2)$ & $147.9(19.9)$ & $176.5(3.3)$ \\
\hline Pallidus & R: $193.6(14.2)$ & $194.1(11.4$ & $152.9(15.6)^{*},^{\ddagger}$ & $183.5(5.5)$ \\
\hline Subthalamic & L: $156.6(14.8)$ & $177.7(11.0)$ & $127.2(11.6)$ & $189.8(29.9)$ \\
\hline Nucleus & R: $173.9(23.7)$ & $186.9(10.5)$ & $132.6(12.0)$ & $196.0(31.2)$ \\
\hline Substantia & L: $227.9(24.3)$ & $222.2(17.1)$ & $189.2(4.2)$ & $193.8(12.7)$ \\
\hline Nigra & R: $228.5(24.1)$ & $220.9(20.1)$ & $190.2(5.8)$ & $198.8(16.2)$ \\
\hline Lateral & L: 263.5 (13.8) & $234.3(10.1)$ & $225.0(17.5)$ & $231.4(15.9)$ \\
\hline Geniculate & $\mathrm{R}: 260.3$ (11.5) & $234.3(4.8)$ & $224.1(17.9)$ & $232.6(17.4)$ \\
\hline Red & L: $237.3(19.5)$ & $234.9(18.3)$ & $184.7(4.1)^{*}$ & $211.2(10.5)$ \\
\hline Nucleus & $\mathrm{R}: 240.6(19.1)$ & $228.8(13.7)$ & $186.3(5.7)^{*} \ddagger$ & $210.9(12.7)$ \\
\hline Superior & L: $251.3(16.8)$ & $204.7(15.0)$ & $197.4(18.3)^{*}$ & $213.7(20.0)$ \\
\hline Colliculus & $\mathrm{R}: 252.6(13.1)$ & $207.2(19.3)$ & $198.7(16.8)^{*}$ & $222.1(13.2)$ \\
\hline Locus & L: 250.3 (27.3) & $228.8(16.0)$ & $203.2(23.6)$ & $234.8(25.9)$ \\
\hline Coeruleus & R: $242.9(19.5)$ & $223.5(13.8)$ & $202.9(16.5)$ & $238.1(24.7)$ \\
\hline Dorsal Tegmental & L: $214.6(25.5)$ & $218.6(14.5)$ & $218.0(20.5)$ & $209.4(11.6)$ \\
\hline Nucleus & R: $210.1(27.6)$ & $211.9(12.5)$ & $219.8(23.8)$ & $207.2(14.9)$ \\
\hline Cerebellar & L: $257.1(18.8)$ & $243.2(8.7)$ & $224.3(22.7)$ & $255.9(12.5)$ \\
\hline Cortex & R: $249.6(17.3)$ & $243.6(10.1)$ & $218.5(24.5)$ & $249.1(11.2)$ \\
\hline
\end{tabular}

${ }^{1}$ Animals received either saline (SAL) or AMPH one day after surgery and were sacrificed 24 hours later.

${ }^{*} \underline{\mathrm{p}}<0.05$ compared to S-SAL; ${ }^{* *} \mathrm{p}<0.01$ compared to S-SAL; ${ }^{\ddagger} \mathfrak{p}<0.05$ compared to S-AMPH 
obtained. The mean optical density readings for each structure was calculated for individual animals and used to calculate the group means for each structure (see Table 1). Thus, we measured the relative (not absolute) values of C.O., as we were interested in the relative differences among the four treatment groups rather than in the absolute amount of C.O. that was present after injury or drug treatment.

\section{Statistical analysis}

For statistical analysis, separate repeated measures analysis of variance were conducted for right and left hemisphere structures, with the individual structure serving as the repeated variable. As side was not treated as a withinsubject factor, the degrees of freedom were inflated. Given the a priori hypothesis of effects being more prevalent in the hemisphere ipsilateral to the lesion, however, we felt that these independent comparisons were warranted. Following the overall analysis incorporating a least-squares approach, we then made comparisons to determine the significance of the main effect (group), with simple main effects comparisons being made among groups using appropriate contrasts (Hays, 1973; Myers, 1979).

\section{RESULTS}

\section{Extent of injury and stain quality}

In both SAL- and AMPH-treated groups, the cortical injuries were similar to those described previously (Sutton \& Feeney, 1992). In all animals, cortical tissue, designated as the hindlimb and forelimb sensorimotor areas (Hall \& Lindholm, 1974), was removed unilaterally (right). Evaluation of histological sections indicated that the lesions extended to the depth of the white matter, from 0.8 to $4.0 \mathrm{~mm}$ lateral to midline, and from 3.5 $\mathrm{mm}$ anterior to $2.0 \mathrm{~mm}$ posterior to bregma in all animals. The underlying hippocampus and caudate were not surgically damaged, and no significant differences were found among the groups with respect to the rostral-caudal, medial-lateral, or dorsal-ventral extent of cortical removal.

Perfusion fixation and the 40-minute reaction in the incubation medium resulted in good differential C.O. staining in various structures and between white- and gray-matter regions. Whereas robust differences in C.O. staining density can be detected by densitometry (see Table 1), the effect of ablation or drug on C.O. depression is difficult to see photographically, so no such illustration is included in this article.

\section{Amphetamine effects in intact animals}

The mean $( \pm \mathrm{SD})$ optical density readings of C.O. activity in the left and right cortex and subcortical structures for the four groups are shown in Table 1. Comparing values for the S-SAL and S-AMPH groups shows that AMPH treatment given to intact animals slightly reduced C.O. activity in several regions, with the greatest reductions occurring within the cerebral cortex, the lateral geniculate, the superior colliculus, and the locus coeruleus. When compared with S-SAL animals, however, this AMPH effect was not significant

\section{Effect of injury on cytochrome oxidase}

In several structures, unilateral cortical ablation induced bilateral reductions in cerebral oxidative metabolism 48 hours post injury. Comparisons between S-SAL and I-SAL groups revealed that right cortical injury resulted in significant reductions in C.O. activity, which was evident within the spared ipsilateral cortical tissue $(p<0.01)$, as well as in the right nucleus accumbens $(p<0.05)$, caudate-putamen $(p<0.05)$, globus pallidus $(p<0.05)$, superior colliculus $(p<0.05)$, and red nucleus $(p<0.05$; see Table 1$)$. Within the contralateral hemisphere, C.O. activity was 
significantly decreased in the I-SAL group (vs. S-SAL animals) in the cerebral cortex $(p<0.01)$, superior colliculus $(\mathrm{p}<0.05)$, and red nucleus $(p<0.03$; Table 1). Comparisons were also made between the S-AMPH and I-SAL groups. Because of the slight reduction of oxidative metabolism in the AMPH-treated intact animals, only the left red nucleus and the right cerebral cortex, globus pallidus, and red nucleus of I-SAL rats showed significantly decreased C.O. activity $(p<0.05$ for all) relative to measures in S-AMPH animals (Table 1).

\section{Amphetamine effects in injured animals}

In animals with unilateral sensorimotor cortex ablation, AMPH treatment eliminated the ablation-induced loss of C.O. staining density, restoring the C.O. stain intensity to near-normal levels (see Table 1). This effect of AMPH was bilateral and global, as the C.O. activity in both the left and the right structures of I-AMPH rats did not differ significantly from the metabolic activity of corresponding structures of either S-SAL or S-AMPH animals. Interestingly, AMPH-induced attenuation of decreased C.O. staining intensity occurred after cortical injury, despite the trend of AMPH to decrease C.O. activity in intact rats.

\section{DISCUSSION}

The results of the current study indicate that restricted, unilateral ablation of the sensorimotor cortex in rat is followed by a widespread reduction in cerebral oxidative metabolism, assessed using C.O. histochemistry. The observed reduction of this mitochondrial enzyme in morphologically intact regions, remote from the site of injury, supports the concept of a remote functional depression or a diaschisis. This concept of distant effects of focal brain injury, mediated by axonal connections to the damaged area and resulting in a suppression of neuronal activity that contributes to symptoms of brain injury, has a long history (see Feeney, 1991 for review). In addition, the current results indicate that a single low dose of AMPH can alleviate the remote metabolic effects that occur following a focal cortical injury.

\section{Effect of brain injury on cerebral metabolism}

Consistent with the results of the current study, the results of numerous studies have demonstrated hypometabolism in regions remote from the primary injury (Ginsberg et al., 1977; Dail et al., 1981; Nemoto et al., 1981; Pappius, 1982; Pappius \& Wolfe, 1983; Kushner et al., 1984; Dauth et al., 1985; Colle et al., 1986; Hovda et al., 1987; Kiyosawa et al., 1987; Lagreze et al., 1987; Beck et al., 1990; Fiorelli et al., 1991; Yoshino et al., 1991; Yoshino et al.,1992; Bergsneider et al., 1997). Widespread and remote metabolic depression after brain injury has typically been studied using 2-deoxy-D-glucose (2-DG) autoradiography to measure the cerebral metabolic rate for glucose. Whereas glucose is well accepted as a primary fuel for consumption by the brain, measurement of ICMRglc by itself provides only limited information regarding the overall metabolic demands and/or dysfunction in brain tissue. Studies incorporating measures of $\mathrm{CBF}$ and oxidative metabolism must also be conducted to assure a more complete understanding of metabolic changes that are produced by brain injury.

To our knowledge, studies specifically addressing CBF following restricted ablation of the cortex have not yet been conducted. CBF has primarily been studied in models of cerebral ischemia (Pulsinelli et al., 1982; Raichle, 1983; Perani et al., 1987; LaManna et al., 1988; Vannucci et al., 1988; Bolander et al., 1989; Dirnagl \& Pulsinelli, 1990; Ginsberg, 1990) and of experimental TBI (Lewelt et al., 1980; Dewitt et al., 1986; McIntosh et al., 1987; Unterberg et al., 1988; Yuan et al., 1988; Yamakami \& McIntosh, 
1989; 1991; Shima \& Marmarou, 1991; Muir et al., 1992). In cases where CBF was not directly measured, the investigators measured ATP (MacMillan, 1982; Pulsinelli \& Duffy, 1983; Fass et al., 1987; Komatsumoto et al., 1987), protein synthesis (Lipton \& Heimbach, 1977; Mies et al. 1991), and extracellular lactate (Pulsinelli \& Duffy, 1983; Prasad et al.,1994; Kawamata et al., 1995) to determine whether flow is, in fact, adequate for energy demands. Following brain injury, these types of studies must be conducted using animals at rest and under stimulated conditions to incorporate and understand the metabolic demands during different physiological conditions. Clearly, such studies are currently impossible to do in the same animal using autoradiographic or tissue content analyses. In an effort to understand the enduring metabolic demand of the brain across both at-rest and activated conditions, many studies have incorporated C.O. histochemistry for measuring oxidative capacity (Hovda et al., 1987; Shaw et al., 1988; Jen et al., 1989; Chiaia et al., 1991; Hovda et al., 1991; Hovda \& Villablanca, 1998).

As the most efficient method of generating ATP, oxidative metabolism tends to run at a relatively constant optimal level (Ackermann \& Lear, 1989; Barinaga, 1997). With its rate of use dictated by the amount of cytochrome $\mathrm{c}$ within the mitochondria, oxidative metabolism can only be upregulated above the maximal level via the manufacture of additional protein. Given that the production of protein can take anywhere from hours to days, cells must rely on a more rapid and dynamic process for satisfying the acute increases in energy demands that are associated with ionic pertubation and/or neuronal firing. It would appear that this quickly responsive process is glycolysis, and this has been the basis for the concept of energy compartmentalization described in both cardiac and brain physiology. This is one of many reasons why, when measurements of glucose metabolism are conducted using 2-DG autoradiography, a physiological steady state must be maintained throughout the uptake period (Sokoloff et al., 1977).

As has been described by many investigators who are interested in the recovery of function following brain injury, the very acute period after injury is often quite dynamic in terms of the energy demands being placed on cells, but the most pronounced feature in the chronic state is a widespread or generalized metabolic depression, as studied using several different techniques. A critical question is whether these longer, more chronic measures of metabolism following injury are simply an index for the current state of the animal over a period of minutes (when 2-DG techniques are used), or whether the overall set point of cerebral metabolism has been fundamentally changed (Hovda et al., 1996; Hovda \& Villablanca, 1998). In previous work on the pharmacology of recovery from brain injury, we took the position, along with others, that injury to the brain results in a pronounced chronic depression of function, reflected in measures of neurotransmitter levels (Krobert et al., 1994), as well as in metabolism. Evidence that drugs enhancing post-injury behavioral recovery also alleviate injury-induced hypometabolism provides support for such concepts as remote functional depression or diaschisis (Feeney et al., 1985; Feeney and Sutton, 1987; Feeney, 1991). In many cases, the metabolic depression that is induced by brain injury may diminish spontaneously, consistent with von Monakow's construct of diaschisis. Unfortunately, von Monakow gave this concept a circular definition, invoking the term diaschisis to explain the spontaneous remission of symptoms after injury. The measures of metabolic dysfunction provide an independent measure of the concept, eliminating his tautology. As demonstrated in the current paper, as well as in prior studies (Feeney et al., 1985; Hovda et al., 1987; Dietrich et al., 1990; Hovda, 1996; Queen et al., 1997), the alleviation of injury-induced metabolic depression can be markedly enhanced with AMPH administration. If, as hypothesized, metabolic depression contributes to behavioral symptoms after brain injury, then 
pharmacological alleviation of the hypometabolism would "enable" dysfunctional neurons so that PT might activate the "performance" circuits that are involved in functional deficits, whose activity may also have been depressed by the injury.

That an indirect catecholaminergic agonist, such as AMPH, would have the ability to alleviate an injury-induced metabolic depression provides some insight into the responsible mechanisms. Over a number of years, we (Feeney et al., 1985; Sutton \& Feeney, 1992; Feeney, 1997; 1998a; 1998b) have advocated an NA hypothesis incorporating the locus coeruleus, with others (Pappius et al., 1988; Pappius, 1991) suggesting that serotonin may be involved. Because AMPH has nonspecific effects, it is important to determine if other drugs releasing NA, such as yohimbine and idazoxan, also improve functional outcome and increase cerebral metabolism. Both yohimbine and idazoxan have been shown to be equivalent to $\mathrm{AMPH}$ in promoting functional recovery in the rat hemiplegia model (Goldstein, 1988; Sutton \& Feeney, 1992). Additionally, these drugs increase cerebral metabolism, as measured by PET-scan studies of rCBF (Schmidt et al., 1995; Bremner et al., 1997). Significantly, similar to the interaction between AMPH and PT to promote recovery, no fixed action of AMPH on cerebral glucose utilization occurs, but rather the activated areas depend upon the task the subject is doing during the period of drug action (Mattay et al., 1996). Whatever the mechanism, clearly an injury-induced metabolic depression is related to the degree and to the extent of recovery of function, given that recovery from deficits is closely correlated with the recovery to normal rates of cerebral metabolism (Hovda, 1996).

\section{Cytochrome oxidase as a marker for oxidative metabolic capacity}

In a number of studies, the C.O. technique has been used to characterize the cerebral oxidative capacity in various brain regions. Some of these studies include investigations addressing cerebral maturation (Dehay \& Kennedy, 1988; Hovda et al., 1992), cerebral decortication (Hovda \& Villablanca, 1998), and the effects of sensory deprivation or stimulation (Kageyama \& Wong-Riley, 1986; WongRiley \& Norton, 1988; Wong-Riley, 1989). As in the current study, previous investigators have used optical densitometry to assess C.O. activity in regions of the cerebrum (Darriet et al., 1986; Hovda et al., 1987, 1991, 1992; Kageyama \& Meyer, 1988; Hovda \& Villablanca, 1990, 1998; Hyde \& Durham, 1990). The intensity of C.O. staining, detected with optical densitometry, correlates highly $(r=.90)$ with C.O. activity as measured using more traditional spectrophotometric techniques (Darriet et al., 1986). The analysis of C.O. staining intensity in the current study revealed several interesting alterations of cerebral oxidative metabolism, induced by AMPH administration and/or cortical ablation.

\section{Effect of amphetamine in sham operates}

Twenty-four hours after a single administration of AMPH, C.O. histochemistry-assessed cerebral oxidative metabolism was moderately decreased in normal, sham-operated rats. AMPH administration in rats has been reported to induce a widespread activation of lCMRglc within 15 minutes (Porrino et al., 1984). Such an acute increase in lCMRglc after AMPH may be related to the rapid increase in NA that has been reported after drug treatment in rats (Krobert et al., 1994). In the current study, the lack of C.O. increase in normal rats given AMPH most likely reflects the fact that oxidative metabolism in normal animals runs at peak efficiency levels and, therefore, cannot be upregulated dynamically by a single injection of AMPH. The depression of C.O. observed in our study may be related to a "post-intoxication" effect of AMPH, reflecting the after effects of an initial global neural activation by this drug. In normal human subjects, AMPH was reported to slightly decrease lCMRglc in cortical regions by 3 hours post-drug (Wolkin et al., 1987). 


\section{Cerebral metabolic depression after brain injury and the effect of amphetamine}

The current results indicate that 48 hours following unilateral sensorimotor cortex ablation, oxidative capacity, assessed by C.O. histochemistry, is decreased in several remote, ipsilateral motor structures, including the nucleus accumbens, caudate-putamen, globus pallidus, red nucleus, and superior colliculus. Prior studies using cortical freezing lesion, ablation, concussion, contusion, or stroke-injury models have also reported a depression of both cerebral oxidative (Dail et al., 1981; Feeney et al., 1985; Hovda et al., 1991; Hovda, 1996;) and glycolytic (Pappius, 1981; Feeney et al., 1985; Colle et al., 1986; Pappius et al., 1988; Sutton et al., 1989a; Dietrich et al., 1990; Yoshino et al., 1991; Queen et al., 1997) metabolism. As with the current findings, such injury-induced metabolic depressions are most evident within the ipsilateral cortical and/or subcortical regions during the first few days post injury. The physiological consequences of these injuryinduced metabolic depressions may be functionally related to the neurobehavioral deficits in the contralateral limbs that are exhibited during this same time period post injury (Feeney et al., 1982; Feeney \& Sutton, 1987, 1988; Gilman et al., 1987; Sutton et al., 1987; Sutton \& Feeney, 1992). AMPH-induced alleviation of metabolic depression may contribute to the ability of the drug to alleviate symptoms (Feeney, 1998b), which has been extended to stroke patients (reviewed in Goldstein, 1993; Feeney, 1997). This effect has also been demonstrated by Hovda and his colleagues (1996), who showed that the AMPH-induced alleviation of metabolic depression following fluid percussion injury was directly related to an increased rate of behavioral recovery.

Prior research on cortical concussion injury (Hovda et al., 1991) revealed that a decrease in C.O. stain intensity appears to be restricted to regions ipsilateral to the injury, and a significant depression is not attained until 5 days post injury. Similarly, the decreased staining of the oxidative enzyme alpha glycerophosphate dehydrogenase that occurs following laceration, ablation, or contusion injury of the sensorimotor cortex, is restricted to regions of the cortex ispilateral to injury and is detectable at 36 hours post injury, and persisting for 9 days (Dail et al., 1981). This enzyme depletion is not lessened by AMPH, but can be prevented by giving the drug during the first 24 hours post injury (Feeney et al, 1985). In the current study, a significant decrease in C.O. activity in the contralateral cerebral cortex, superior colliculus, and red nucleus was evident 2 days following ablation of the right sensorimotor cortex. This finding may indicate that for the detection of depressed oxidative metabolism, the C.O. histochemistry method is more sensitive than staining for alpha glycerophosphate dehydrogenase activity (Feeney et al., 1985). The relatively early, bilateral depression of C.O. activity after suction ablation but not after concussion, produced by fluid percussion (Hovda et al., 1991), suggests that either the severity of injury or the trauma model used influences both the extent and the onset of significant metabolic depression. Unlike ablation, after contusion of the sensorimotor cortex, an increase in C.O. in the ipsilateral auditory and entorhinal cortex has been observed (Weisend et al., 1990). This increase in C.O. after contusion injury may be related to the recurring seizures that have been reported after this type of injury (Krobert et al., 1992; Nilsson et al., 1994).

The current results indicate that acute administration of AMPH (24 hours after injury) is capable of attenuating the bilateral remote functional depression of oxidative metabolism that is produced by unilateral cortical ablation. That AMPH treatment alleviated the depressed oxidative metabolism in all structures examined suggests that the drug exhibits a global effect on neural metabolism. This result is consistent with the hypothesis that AMPH may exert its effects on cerebral metabolism via actions either on the noradrenergic (Feeney et al., 1985; Feeney \& 
Sutton, 1987; 1988; Feeney 1998b) or on the serotonergic (Pappius, 1991) neurotransmitter systems, which provide diffuse cerebral innervation.

That bilateral reductions in C.O. were found in some structures (for example, cerebral cortex, red nucleus, and superior colliculi) after unilateral sensorimotor cortex ablation, and that AMPH treatment alleviated both ipsilateral and contralateral depression of oxidative capacity in injured rats may not, at first glance, appear to be compatible with the hypothesis that the druginduced alleviation of hypometabolism is related to functional recovery. Nevertheless, some evidence exists for a role of the contralateral hemisphere in recovery (Dietrich et al., 1990). Most studies on the effect of AMPH on functional recovery after unilateral cortex ablation have employed the beam-walking scale developed by Feeney and colleagues (Feeney et al., 1982; Sutton \& Feeney, 1992) for assessing contralateral hindlimb dysfunction. Albeit this rating scale for assessing the recovery from hemiplegia focuses on the ability of the injured animal to use the contralateral hindlimb, in some animals mild and transient deficits in the use of the ipsilateral hindlimb have been observed during beam-walk tests. When using the scale to rate both ipsilateral and contralateral limbs during beam-walk testing, a very mild and transient deficit can be seen in the ipsilateral hindlimb (Feeney, personal observation), which may contribute to the inability of some rats to traverse the beam during the first few days after injury. Mild and transient deficits in the hindlimb ipsilateral to cortical contusion injury (specifically, delayed response times to retract the limb after lateral and posterior displacement (Sutton et al., 1990), has also been observed. At present, we can only speculate that a bilateral decrease in oxidative capacity may contribute to these bilateral deficits, and that an AMPH-induced alleviation of this decreased oxidative metabolism may facilitate recovery in both the ipsilateral and the contralateral limbs. Firm conclusions will depend upon further studies employing both behavioral tasks that are sensitive to potential bilateral deficits and analyses of potential bilateral metabolic responses to injury and/or drug treatment.

In conclusion, this study has demonstrated that a single AMPH treatment attenuates the depression of the cerebral oxidative metabolism that occurs after unilateral sensorimotor cortex ablation. We previously reported that AMPH treatment attenuates the decrease in ICMRglc and the paling of alpha glycerophosphate dehydrogenase staining that occurs after sensorimotor cortex injury (Feeney et al., 1985; Queen et al., 1997). Likewise, Dietrich et al. (1990) reported that AMPH treatment increases lCMRglc in cortical regions following photochemically induced cortical infarcts. These effects of AMPH on cerebral metabolism after cortical injury support a general hypothesis (Feeney et al., 1985; Hovda et al., 1987; Feeney \& Sutton, 1987, 1988; Feeney, 1991; Feeney, 1998a, 1998b) that AMPH may exert its beneficial effects on behavioral recovery by alleviating a metabolic dysfunction (namely, a remote functional depression) that is induced by cortical injury.

\section{ACKNOWLEDGMENTS}

The authors would like to thank Dr. Oscar Scrimen for the use of his densitometer. This work was supported by DHHS Grants 1-R01NS0220 and 3-S06-RR08139, the University of New Mexico, and by the U.S. Army Medical Research and Development Command under Grant No. DAMD17-91-Z-1006. Opinions, interpretations, conclusions, and recommendations are those of the authors and are not necessarily endorsed by the U.S. Army. In conducting research using animals, the investigators adhered to the "Guide for the Care and Use of Laboratory Animals", prepared by the Committee on Care and Use of Laboratory Animals of the Institute of Laboratory Animal Resources, National Research Council (NIH Publication No. 86-23, Revised 1985). 


\section{REFERENCES}

Ackermann RF, Lear JL. Glycolysis-induced discordance between glucose metabolic rates measured with radiolabeled fluorodeoxyglucose and glucose. J Cereb Blood Flow Metab 1989; 9: 774-785.

Barinaga $M$. What makes brain neurons run? Science 1997; 276: 196-198.

Bath PMW. Treating acute ischaemic stroke. British Med J International; 1995; 311: 139-140.

Beck T, Wree A, Schleicher A. Glucose utilization in rat hippocampus after long-term recovery from ischemia. J Cereb Blood Flow Metab 1990; 10: 542-549.

Bergsneider M, Hovda DA, Shalmon E, Kelly DF, Vespa P, Martin NA, et al. Cerebral hyperglycolysis following severe human TBI: A positron emission tomography study. J Neurosurg 1997; 86: 241-251.

Bolander HG, Persson L, Hillered L, D'Argy, R, Ponten, U, Olsson Y. Regional cerebral blood flow and histopathologic changes after middle cerebral artery occlusion in rats. Stroke 1989; 20: 930-837.

Boyeson MG, Feeney DM. Intraventricular norepinephrine facilitates motor recovery following sensorimotor cortex injury. Pharmacol Biochem Behav 1990; 35: 497-501.

Boyeson MG, Feeney DM. Adverse effects of catecholaminergic drugs following unilateral cerebellar ablations. Rest Neurol Neurosci 1991; 3: 227-233.

Boyeson MG, Harmon RL. Effects of trazadone and desipramine on motor recovery in brain-injured rats. Am J Phys Med Rehab 1993; 72: 286-293.

Boyeson MG, Harmon RL, Jones JL. Comparative effects of fluoxetine, amitriptyline and serotonin on functional motor recovery after sensorimotor cortex injury. Am J Med Rehab 1994; 73: 7683.

Brailowsky S, Knight RT, Blood K, Scabini D. Gamma-aminobutyric acid-induced potentiation of cortical hemiplegia. Brain Res 1986; 362: $322-330$

Bremner JD, Innis RB, Ng CK, Staib LH, Salomon RM, Bronen RA, et al. Positron emission tomography measurement of cerebral metabolic correlates of yohimbine administration in combat-related posttraumatic stress disorder. Arch Gen Psychiatry 1997; 54: 246-254.

Chiaia NL, Bennett-Clarke CA, Rhoades, RW. Effects of cortical and thalamic lesions upon primary afferent terminations, distributions of projection neurons, and the cytochrome oxidase pattern in the trigeminal brainstem complex. $\mathrm{J}$ Comp Neurol 1991; 303: 600-616.

Colle LM, Holmes LJ, Pappius HM. Correlation between behavioral status and cerebral glucose utilization in rats following freezing lesion. Brain Res 1986; 397: 27-36.

Dail WG, Feeney DM, Murray HM, Linn RT, Boyeson MG. Responses to cortical injury. II. Widespread depression of the activity of an enzyme in cortex remote from a focal injury. Brain Res 1981; 211: 79-89.

Darriet D, Der T, Collins RC. Distribution of cytochrome oxidase in rat brain: Studies with diaminobenzidine histochemistry in vitro and $\left[{ }^{14} \mathrm{C}\right]$ cyanide tissue labeling in vivo. $\mathrm{J}$ Cereb Blood Flow Metab 1986; 6: 8-14.

Dauth GW, Gilman S, Frey KA, Penney JB. Basal ganglia glucose utilization after recent precentral ablation in the monkey. Ann Neurol 1985; 17: 431-438.

Dehay C, Kennedy $\mathrm{H}$. The maturational status of thalamocortical and callosal connections of visual areas V1 and V2 in the newborn monkey. Behav Brain Res 1988; 29: 237-244.

Dewitt D S, Jenkins LW, Wei EP, Kontos HA, Becker DP. The effects of fluid percussion brain injury on regional and total cerebral blood flow and pial vessel diameter. A combined pial window and microsphere study. J Neurosurg 1986; 64: 787-794.

Dietrich WD, Alonso O, Busto R, Ginsberg MD. The effect of amphetamine on functional brain activation in normal and post-infarcted rat. Stroke 1990; 21 sIII: $147-150$.

Dirnagl U, Pulsinelli WA. Autoregulation of cerebral blood flow in experimental focal brain ischemia. J Cereb Blood Flow Metab 1990; 10: 327-336.

Fass B, Ramirez JJ, Stein DG, Mahadik SP, Karpiak SE. Ganglioside-induced alterations in hippocampal cholinergic enzymes and $\mathrm{Na}, \mathrm{K}$ ATPase after fimbria-fornix transection. J Neurosci Res 1987; 17: 45-50.

Feeney DM. Pharmacologic modulation of recovery after brain injury: A reconsideration of diaschisis. J Neuro Rehab 1991; 5: 113-128.

Feeney DM. From laboratory to clinic: Noradrenergic enhancement of physical therapy for stroke or trauma patients. In: Freund H-J, Sabel BA, Witte OW, eds, Brain Plasticity; Adv Neurol, Vol. 73; Philadelphia: Lippencott-Raven Publishers, 1997; 383-394. 
Feeney DM. Rehabilitation pharmacology: Noradrenergic enhancement of physical therapy. In: Ginsberg M, Bogousslavsky J, eds, Cerebrovascular Disease: Pathophysiology, Diagnosis and Management, Vol I; Cambridge, MA: Blackwell Scientific Press, 1998a; 620-636.

Feeney DM. Mechanisms of noradrenergic modulation of physical therapy: Effects on functional recovery after cortical injury. In: Goldstein LB, ed, Restorative Neurology, Advances in the Pharmacology of Recovery After Stroke. Armonc, New York: Futura Publishing Co., 1998b; 35-78.

Feeney DM, Barela PB, Heard DF, Weisend MP. Secondary neuronal death and gliosis: comparison of cortical trauma, ablation and protective effects of ketamine. J Neurotrauma 1989; 6: 209.

Feeney DM, Baron J-C. Diaschisis. Stroke 1986; 17: 817-830.

Feeney DM, Gonzalez A, Law WA. Amphetamine, haloperidol and experience interact to affect rate of recovery after motor cortex injury. Science 1982; 217: 855-857.

Feeney DM, Hovda DA. Reinstatement of binocular depth perception by amphetamine and visual experience after visual cortex ablation. Brain Res 1985; 342: 352-356.

Feeney DM, Sutton RL. Pharmacotherapy for recovery of function after brain injury. CRC Crit Rev Neurobiol 1987; 3: 135-197.

Feeney DM, Sutton RL. Catecholamines and recovery of function after brain damage. In: Stein DG, Sabel BA, eds, Pharmacological Approaches to the Treatment of Central Nervous System Injury. New York: Plenum Press, 1988; 121-142.

Feeney DM, Sutton RL, Boyeson MG, Hovda DA, Dail WG. The locus coeruleus and cerebral metabolism: Recovery of function after cortical injury. Physiol Psych 1985; 13: 197-203.

Feeney DM, Weisend MP, Kline AE. Noradrenergic pharmacotherapy, intracerebral infusion and adrenal transplantation promote functional recovery after cortical damage. J Neur Transplant Plast 1994; 4: 199-214.

Feeney DM, Westerberg VS. Norepinephrine and brain damage: Alpha noradrenergic pharmacology alters functional recovery after cortical trauma. Can J Psych 1990; 44: 233-252.

Fiorelli M, Blin J, Bakchine S, Laplane D, Baron JC. PET studies of cortical diaschisis in patients with motor hemi-neglect. J Neurol Sci 1991; 104: 135-142.

Gilman S, Dauth GW, Frey KA, Penney JB. Exper- imental hemiplegia in the monkey: Basal ganglia glucose activity during recovery. Ann Neurol 1987; 22: 370-376.

Ginsberg MD. Local metabolic responses to cerebral ischemia. Cerebrovas Brain Metab Rev 1990; 2 : 58-93.

Ginsberg MD, Pulsinelli WA. The ischemic penumbra, injury thresholds, and the therapeutic window for acute stroke. Ann Neurol 1994; 36: 553-554.

Ginsberg MD, Reivich M, Giandomenico A, Greenberg JH. Local glucose utilization in acute focal cerebral ischemia: Local dysmetabolism and diaschisis. Neurology 1977; 27: 1042-1048.

Gold PE, Delanoy RL, Merrin J. Modulation of long-term potentiation by peripherally administered amphetamine and epinephrine. Brain Res 1984; 305: 103-107.

Goldstein LB. Amphetamine facilitated functional recovery after stroke. In: Ginsberg MD, Dietrich WD, eds, The 16th Princeton Conference on Cerebral Vascular Diseases. New York: Raven Press, 1988; 303-308.

Goldstein LB. Basic and clinical studies of pharmacologic effects on recovery from brain injury. $\mathrm{J}$ Neural Transplant Plast 1993; 4: 175-192

Goldstein LB, Davis JN. Post-lesion practice and amphetamine-facilitated recovery of beam-walking in the rat. Behav Neurosci 1990; 104: 318-325

Hall RD, Lindholm EP. Organization of motor and somatosensory neocortex in the albino rat. Brain Res 1974; 66: 23-38.

Hays WL. Statistics for the Social Sciences. New York: Winston, 1973.

Hosokawa S, Kato M, Aiko Y, Shima F. Altered local cerebral glucose utilization by unilateral frontal cortical ablations in rats. Brain Res 1985; 343: 8-15.

Hovda DA. Metabolic dysfunction. In: Narayan RK, Qilberger JE, Povlishock JE, eds, Neurotrauma. New York: McGraw-Hill, 1996; 1459 1478.

Hovda DA, Chugani HT, Villablanca JR, Badie B, Sutton RL. Maturation of cerebral oxidative metabolism in the cat: A cytochrome oxidase histochemistry study. J Cereb Blood Flow Metab 1992; 12: 1039-1048.

Hovda DA, Feeney DM. Amphetamine with experience promotes recovery of locomotor function after unilateral frontal cortex injury in the cat. Brain Res 1984; 298: 358-361.

Hovda DA, Sutton RL, Feeney DM. Recovery of tactile placing after visual cortex ablation in cat: A behavioral and metabolic study of diaschisis. 
Exp Neurol 1987; 97: 391-402.

Hovda DA, Villablanca JR. Sparing of visual field perception in neonatal but not adult cerebral hemispherectomized cats. Relationship with oxidative metabolism of the superior colliculus. Behav Brain Res 1990; 37: 119-132.

Hovda DA, Villablanca JR. Cerebral metabolism following neonatal or adult hemineodecortication in cats: Effects on oxidative capacity using cytochrome oxidase histochemistry. Dev Brain Res 1998; 110: 39-50.

Hovda DA, Villablance JR, Chugani HT, Phelps ME. Cerebral metabolism following neonatal or adult hemineodecortication in cats: I. Effects on glucose metabolism using $\left[{ }^{14} \mathrm{C}\right] 2$-deoxy-D-glucose autoradiography. J Cereb Blood Flow Metab 1996; 16: 134-146.

Hovda DA, Yoshino A, Kawamata T, Katayama Y, Becker DM. Diffuse prolonged depression of cerebral oxidative metabolism following concussive brain injury in the rat: A cytochrome oxidase histochemistry study. Brain Res 1991; 567: 1-10.

Hurwitz BE, Dietrich WD, McCabe PM, Alonso O, Watson BD, Ginsberg MD, Schneiderman N. Amphetamine promotes recovery from sensorymotor integration deficit after thrombotic infarction of the primary somatosensory rat cortex. Stroke 1991; 22: 648-654.

Hyde GE, Durham D. Cytochrome oxidase response to cochlea removal in chicken auditory brain-stem neurons. J Comp Neurol 1990; 297: 329-339.

Jen LS, Zhao LP, Chau RMW. Cytochrome oxidase activity in the rat retina following unilateral thalamic lesion. Neurosci Lett 1989; 103: 133-138.

Kageyama GH, Meyer RL. Laminar histochemical and cytochemical localization of cytochrome oxidase in the goldfish retina and optic tectum in response to deafferentation and during regeneration. J Comp Neurol 1988; 278: 521-542.

Kageyama GH, Wong-Riley M. Differential effect of visual deprivation on cytochrome oxidase levels in major cell classes of the cat LGN. J Comp Neurol 1986; 246: 212-237.

Kawamata T, Katayama Y, Hovda DA, Yoshino A, Becker DP. Lactate accumulation following concussive brain injury: The role of ionic fluxs induced by excitatory amino acids. Brain Res 1995; 674:. 196-204.

Kiyosawa M, Pappata S, Duverger D, Richie D, Cambon H, Mazoyer B, et al. Cortical hypometabolism and its recovery following nucleus basalis lesions in baboons: A PET study. J Cereb Blood Flow Metab 1987; 7: 812-817.
Khan N, Hajek M, Antonini A, Maguire P, Muller S, Valavanis A, et al. Cerebral metabolic changes (18F-FDG PET) during selective anterior temporal lobe amobarbital test. Eur Neurol 1997; 38: 268-275.

Komatsumota S, Nioka S, Greenberg JH, Yoshizaki K, Subramanian VH, Chance B, Reivich M. Cerebral energy metabolism measured in vivo by $31 \mathrm{P}$ NMR in middle cerebral artery occlusion in the cat: Relation to severity of stroke. J Cereb Blood Flow Metab 1987; 7: 557-562.

Krobert KA, Salazar RA, Sutton RL, Feeney DM. Temporal evolution of histopathology and unit activity in rat hippocampal CA3 region after focal cortical contusion. J Neurotrauma 1992; 9: 64.

Krobert KA, Sutton RL, Feeney DM. Spontaneous and amphetamine evoked release of noradrenaline after cortical contusion. J Neurochem 1994; 62: 2233-2240.

Kushner M, Alavi A, Reivich M, Dann R, Burke A, Robinson G. Contralateral cerebellar hypometabolism following cerebral insult: A positron emission tomographic study. Ann Neurol 1984; 15: 425-434.

Lagreze HL, Levine RL, Pedula KL, Nickles RJ, Sunderland JS, Rowe BR. Contralateral flow reduction in unilateral stroke: Evidence for transhemispheric diaschisis. Stroke 1987; 18: 882886.

Lamanna JC, Crumrine RC, Jackson DL. No correlation between cerebral blood flow and neurologic recovery after reversible total cerebral ischemia in the dog. Exp Neurol 1988; 101: 234-247.

Lewelt W, Jenkins LW, Miller JD. Autoregulation of cerebral blood flow after experimental fluid percussion injury of the brain. J Neurosurg 1980; 53: 500-511.

Lipton P, Heimbach CJ. The effect of extracellular potassium concentration on protein synthesis in guinea pig hippocampal slices. J Neurochem 1977; 28: 1347-1354.

Macmillan V. Cerebral Na+, K+-ATPase activity during exposure to and recovery from acute ischemia. J Cereb Blood Flow Metab 1982; 2: 457-465.

Mattay VS, Berman KF, Ostrem JL, Esposito G, Van Horn JD, Bigelow LB, Weinberger DR. Dextroamphetamine enhances "neural networkspecific" physiological signals: A positron-emission tomography rCBF study. J Neurosci 1996; 16 : 4816-4822.

McIntosh TK, Hayes RL, Dewitt DS, Agura V, 
Faden AI. Endogenous opioids may mediate secondary damage after experimental brain injury. Am J Physiol 1987; 253: E565-E574.

Mies G, Ishimaru S, Xie Y, Seo K, Hossmann K-A. Ischemic thresholds of cerebral protein synthesis and energy state following middle cerebral artery occlusion in rat. $\mathrm{J}$ Cereb Blood Flow Metab 1991; 11: 753-761.

Mintz M, Toner R. Exposure to amphetamine after substantia nigra lesion interferes with the process of behavioral recovery. Pharm Biochem Behav 1989; 25: 1307-1311.

Muir JK, Boerschel M, Ellis EF. Continuous monitoring of posttraumatic cerebral blood flow using laser-doppler flowmetry. J Neurotrauma 1992; 9: 355-362.

Myers JL. Fundamentals of Experimental Design. Boston: Allyn and Bacon, 1979.

Nemoto EM, Hossmann K-A, Cooper HK. Postischemic hypermetabolism in cat brain. Stroke 1981; 12: 666-676.

Nilsson P, Ronne-Engstrom E, Flink R, Ungerstedt U, Carlson H Hillered L. Epileptic seizure activity in the acute phase following cortical impact trauma in rat. Brain Res 1994; 637: 227-232

Pappius HM. Local cerebral glucose utilization in thermally traumatized rat brain. Ann Neurol 1981; 9: 484-491.

Pappius HM. Dexamethasone and local cerebral glucose utilization in freeze-traumatized rat brain. Ann Neurol 1982; 12: 157-162.

Pappius HM. Brain injury: New insights into neurotransmitter and receptor mechanisms. Neurochem Res 1991; 16: 941-949.

Pappius HM, Dadoun R, McHugh M. The effect of p-chlorophenylalanine on cerebral metabolism and biogenic amine content of traumatized brain. J Cereb Blood Flow Metab 1988; 8: 324-334.

Pappius HM, Wolfe LS. Effects of indomethacin and ibuprofen on cerebral metabolism and blood flow in traumatized brain. J Cereb Blood Flow Metab 1983; 3: 448-459.

Perani D, Gerundini P, Lenzi GL. Cerebral hemispheric and contralateral cerebellar hypoperfusion during a transient ischemic attack. J Cereb Blood Flow Metab 1987; 7, 507-509.

Porrino LJ, Lucignani G, Dow-Edwards D, Sokoloff L. Correlation of dose-dependent effects of acute amphetamine administration on behavior and local cerebral metabolism in rats. Brain Res 1984; 307: 311-320.

Prasad MR, Ramaiah C, McIntosh TK, Dempsey RJ, Hipkens S, Yurek D. Regional levels of lactate and norepinephrine after experimental brain injury. J Neurochem 1994; 63: 1086-1094.

Pulsinelli WA, Duffy TE. Regional energy balance in rat brain after transient forebrain ischemia. $\mathrm{J}$ Neurochem 1983; 40: 1500-1503.

Pulsinelli WA, Levy DE, Duffy TE. Regional cerebral blood flow and glucose metabolism following transient forebrain ischemia. Ann Neurol 1982; 11: 499-509.

Queen S, Chen M, Feeney DM. Amphetamine alleviates the reduced local cerebral glucose utilization produced by TBI. Brain Res 1997; 777: 42-50.

Raichle ME. The pathophysiology of brain ischemia. Ann Neurol 1983; 13: 2-10.

Robbins TW, Everitt BJ, Cole BJ, Archer T, Mohammed A. Functional hypotheses of the coeruleocortical noradrenergic projection: A review of recent experimentation and theory. Physiol Psych 1985; 13: 127-150.

Salo AA, Feeney DM. Reduction of morbidity, mortality and lesion size in rat model of cerebral infarction with amphetamine. Soc Neurosci, Abst 13, 1987; 1268.

Schmidt ME, Matochik JA, Risinger RC, Schouten JL, Zametkin AJ, Cohen RM, et al. Regional brain glucose metabolism after acute alpha Zblockade by idazoxan. Clin Pharmacol Ther 1995; 57: 684-695.

Segal M, Bloom FE. The action of norepinephrine in the rat hippocampus. III. Hippocampal cellular responses to locus coeruleus stimulation in the awake rat. Brain Res 1987; 107: 499-511.

Segal M, Bloom FE. The action of norepinephrine in the rat hippocampus. IV. The effects of locus coeruleus stimulation on evoked hippocampal unit activity. Brain Res 1976b; 107: 513-525.

Shaw C, Prusky G, Cynader M. Surgical undercutting prevents receptor redistribution in developing kitten visual cortex. Visual Neurosci 1988; 1: 205-210.

Shima K, Marmarou A. Evaluation of brain-stem dysfunction following severe fluid-percussion head injury to the cat. J Neurosurg 1991; 74: 270-277.

Sokoloff L, Reivich M, Kennedy C, Des Rosiers MH, Patlak CS, Pettigrew KD, et al. The [14C]deoxyglucose method for the measurement of local cerebral glucose utilization: Theory, procedure, and normal values in the conscious and anesthetized albino rat. J Neurochem 1977; 28: 897-916.

Sutton RL, Feeney DM. Alpha-Noradrenergic agonists and antagonists affect recovery and maintenance 
of beam-walking ability after sensorimotor cortex ablation in the rat. Restor Neurol Neurosci 1992; 4: 1-11.

Sutton RL, Hovda DA, Chugani HT. Time course of local cerebral glucose utilization (LCGU) alterations after motor cortex ablation in the rat. Soc Neurosci, Abst 15, 1989a; 128.

Sutton RL, Hovda DA, Feeney DM. Ampetamine accelerates recovery of locomotor function following bilateral frontal cortex ablation in cats. Behav Neurosci 1989b; 103: 837-841.

Sutton RL, Lescaudron L, Stein DG. Behavioral consequences of moderate and severe cortical contusion in the rat. Soc Neurosci, Abst 16, 1990; 777.

Sutton RL, Weaver MS, Feeney DM. Drug-induced modifications of behavioral recovery following cortical trauma. J Head Trauma Rehab 1987; 2: 50-58.

Unterberg AW, Andersen BJ, Clarke GD, Marmarou A. Cerebral energy metabolism following fluidpercussion brain injury in cats. $J$ Neurosurg 1988; 68: 594-600.

Vannucci RC, Lyons DT, Vasta F. Regional cerebral blood flow during hypoxia-ischemia in immature rats. Stroke 1988; 19: 245-250.

Walker-Batson D, Smith P, Curtis S, et al. Amphetamine paired with physical therapy accelerates motor recovery following stroke: Further evidence. Stroke 1995; 26: 2254-2259.

Walker-Batson D, Unwin H, Curtis S, et al. Use of amphetamine in the treatment of aphasia. Restor Neurol Neurosci 1992; 4: 47-50.

Weisend MP, Salazar RA, Feeney DM. Sensorimotor contusion but not ablation increases cytochrome oxidase activity in rat auditory and entorhinal cortex. 8th Annual Meeting of the Neurotrauma Society, St. Louis, MO, 1990.

Wolkin A, Angrist B, Wolf A, Brodie J, Wolkin B, Jaeger J, et al. Effects of amphetamine on local cerebral metabolism in normal and schizophrenic subjects as determined by positron emission tomography. Psychopharmacol 1987; 92: 241-246.

Wong-Riley MTT. Changes in the visual system of monocularly sutured or enucleated cats demonstrable with cytochrome oxidase histochemistry. Brain Res 1979; 171: 11-28.

Wong-Riley MTT. Cytochrome oxidase: An endogenous metabolic marker for neuronal activity. Trends Neurosci 1989; 12: 94-101.

Wong-Riley MTT, Norton TT. Histochemical localization of cytochrome oxidase activity in the visual system of the tree shrew: Normal patterns and the effect of retinal impulse blockage. $\mathrm{J}$ Comp Neurol 1988; 272: 562-578.

Woodard DJ, Moises HC, Waterhouse BD, Hoffer BJ, Freedman R. Modulatory actions of norepinephrine in the central nervous system. Fed Proc 1979; 38: 2109-2116.

Yamakami I, McIntosh TK. Effects of TBI on regional cerebral blood flow in rats as measured with radiolabeled micro-spheres. J Cereb Blood Flow Metab 1989; 9: 117-124.

Yamakami I, McIntosh TK. Alterations in regional cerebral blood flow following brain injury in the rat. J Cereb Blood Flow Metab 1991; 11: 655-660.

Yoshino A, Hovda DA, Kawamata T, Katayama Y, Becker DP. Dynamic changes in local cerebral glucose utilization following cerebral concussion in rats: Evidence of a hyper- and subsequent hypometabolic state. Brain Res 1991; 561: 106-119.

Yoshino A, Hovda DA, Katayama Y, Kawamata T, Becker DP. Hippocampal CA3 lesion prevents post-concussive metabolic dysfunction in CA1. J Cereb Blood Flow Metab 1992; 12: 9961006.

Yuan X, Prough DS, Smith TL, Dewitt DS. The effects of TBI on regional cerebral blood flow in rats. J Neurotrauma 1988; 5: 289-301.

Note added in proof: A color photo illustrating the effects of brain injury on cytochrome oxidase is available on the internet web site of $D$. Feeney: http://www.unm.edu/ feeney/index.html 

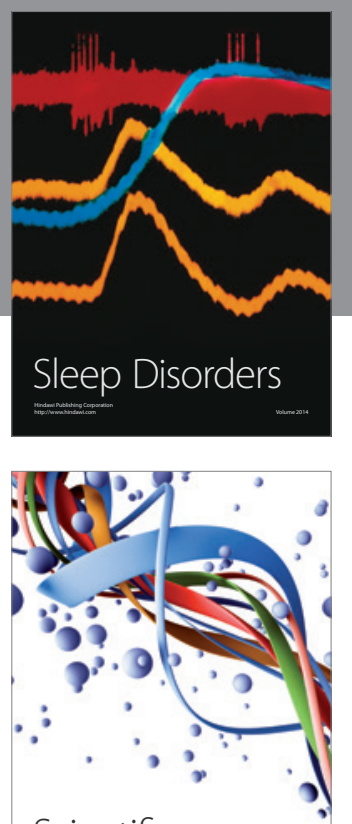

Scientifica
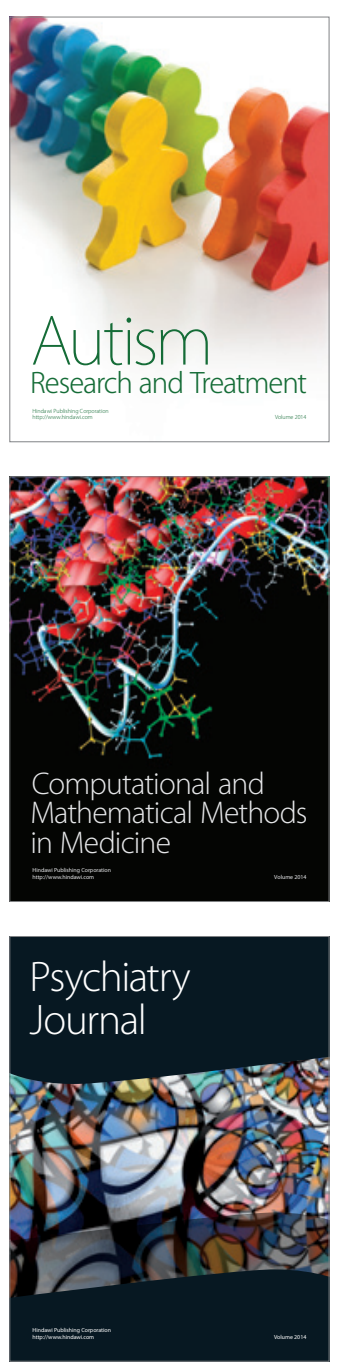
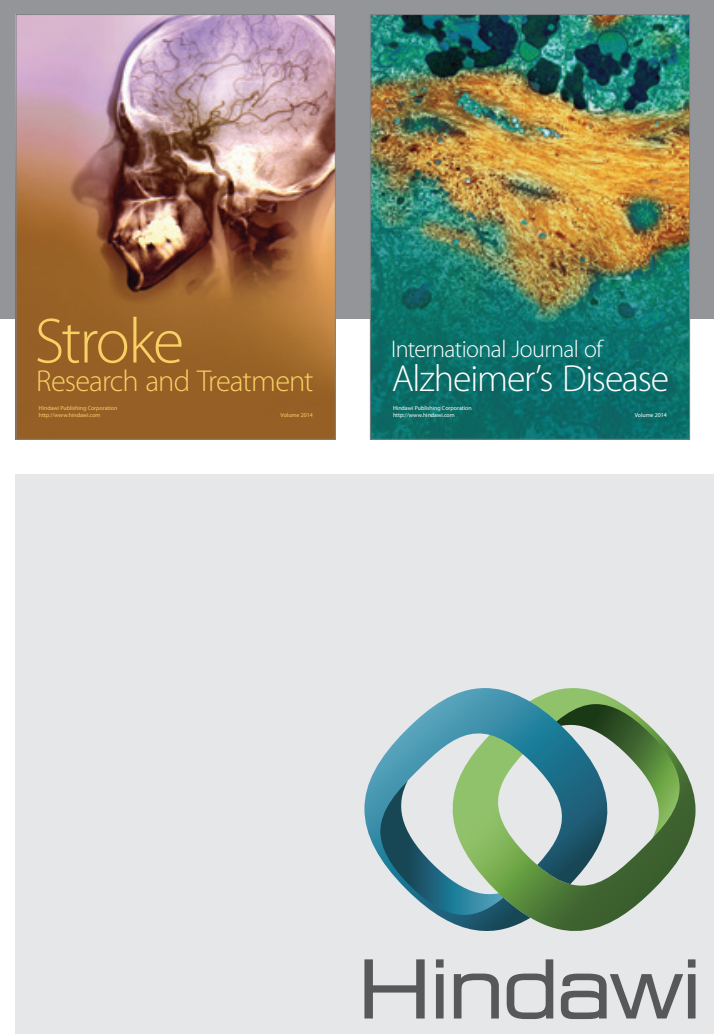

Submit your manuscripts at

http://www.hindawi.com
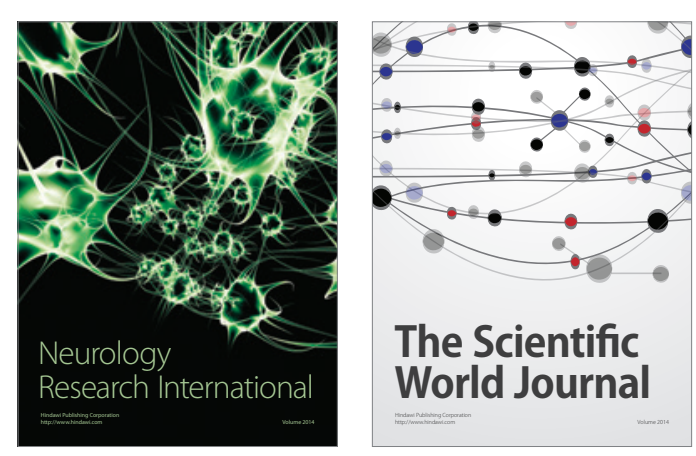

The Scientific World Journal

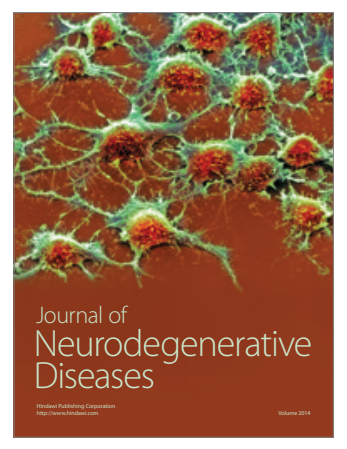

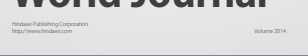

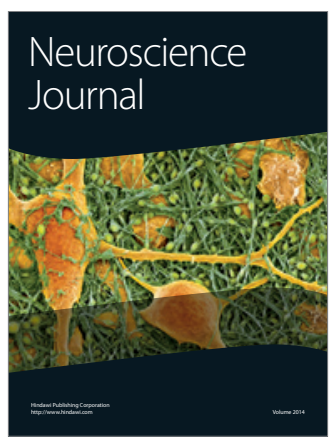

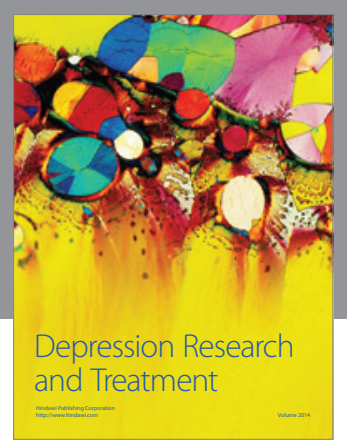
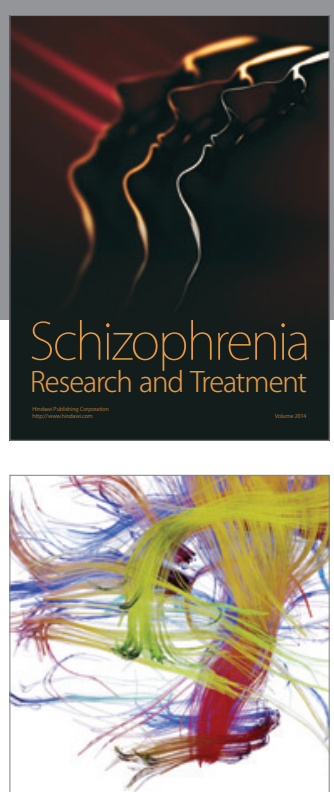

Brain Science

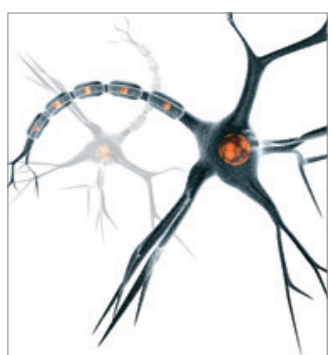

Neural Plasticity
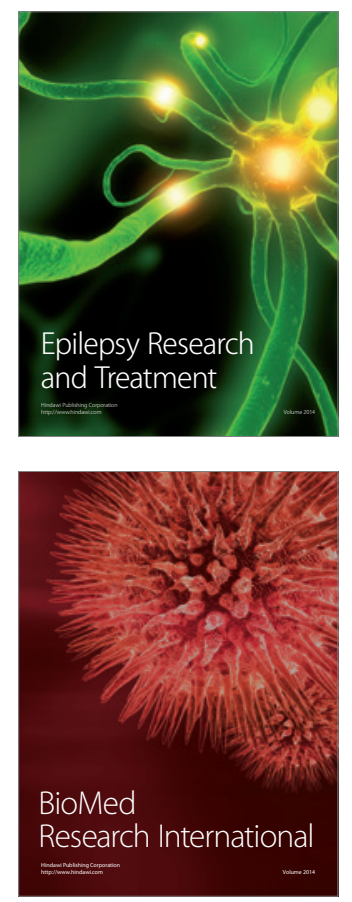

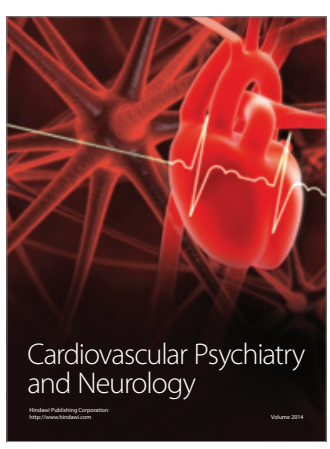

Parkinson's

Disease
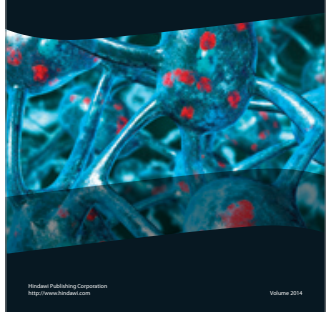